\title{
Toward a Model of Cross-Cultural Business Ethics: The Impact of Individualism and Collectivism on the Ethical Decision-Making Process
}

\author{
Bryan W. Husted David B. Allen
}

ABSTRACT. In this paper, we explore the impact of individualism and collectivism on three basic aspects of ethical decision making - the perception of moral problems, moral reasoning, and behavior. We argue that the inclusion of business practices within the moral domain by the individual depends partly upon individualism and collectivism. We also propose a pluralistic approach to post- conventional moral judgment that includes developmental paths appropriate for individualist and collectivist cultures. Finally, we argue that the link between moral judgment and behavior is related to individualism and collectivism.

KEY WORDS: individualism, collectivism, cross-cultural ethics, ethical decision making, moral reasoning

Introduction

One of the recent challenges of international management research has been to help managers understand business ethics across different cultures. Why are certain practices tolerated more by some cultures than others? For example, we know that software piracy is more common in Asia than in the United States (Donaldson, 1996; Swinyard et al., 1990). We also know that job security is a more important ethical concern in Japan than in Canada (Nyaw and Ng, 1994). Unfortunately, we know little about how culture affects the perception and evaluation of practices such as software piracy and job security or how it affects subsequent behavior. A careful analysis of the relationship between different cultural dimensions and ethical decision making by individuals in organizations might elucidate our understanding. For our purposes here, ethical decision making refers to discretionary decision-making behavior, which "determin[es] how conflicts in human interests are to be settled and ... optimiz[es] mutual benefit ... [for] people living together in groups" (Hardin, 1988; Rest, 1986, p. 1; Trevino, 1986).

The literature includes several models of ethical decision making by individuals (Jones, 1991; Rest, 1986; Trevino, 1986). They share three elements: (1) perception of a moral problem (the moral domain), (2) processes of moral reasoning (judgment), and (3) behavior. However, these models largely differ in the conceptualization of the reasoning-behavior link. Rest (1986) and Jones (1991) both say that this relationship is mediated by moral intention. Jones (1991) adds that the intensity of the moral issue also moderates this relationship. Trevino (1986) argues that the reasoning- behavior relationship is moderated by individual and situational factors. None of these models provide for a specific role attributable to societal culture.

Trevino (1992) suggests that Kohlberg's moral judgment theory could be used as a framework to study the impact of societal culture on business ethics. This paper deliberately builds on Trevino's $(1986,1992)$ model because it serves as a least common denominator for ethical decision-making models. In particular, preliminary research provides empirical support for her model (Trevino and Youngblood, 1990; Trevino et al., 1998; Wimbush, 1999).

Moreover, it also allows for, although does not explicitly include, societal culture as a situational variable in the ethical decision-making process.

It should be recognized that all these models suffer from an individualistic bias (Gergen, 1999). The original groupthink analyses demonstrate how group processes may lead to irresponsible organizational behavior (Janis, 1982). These processes are not captured by these ethical-reasoning models. People rarely make 
ethical decisions that are directly implemented by organizations. Despite the bias in these models, people do make decisions that affect their individual behavior. In addition, individuals perceive problems and make judgments that affect collective behavior. Accordingly, understanding the impact of culture on ethical perceptions, judgments, and behaviors will be useful to culture-spanning managers who work with individuals in multicultural teams or deal with negotiators from different cultures.

Elsewhere in the literature, recent work has begun to relate culture to ethical decision making. Wines and Napier (1992) develop a model that emphasizes the impact of societal, corporate, and family culture on the manager's values, without specifying any theoretical propositions. Vitell et al. (1993) then use Hofstede's (1984) cultural dimensions to deduce specific propositions relating culture to the perception of ethical problems and the consequences of behavior. Cohen et al. (1996) develop an inductive model of the impact of culture on the perception of ethical problems, though the authors themselves recognize that other aspects of the ethical decision- making process, like moral reasoning and behavior, need to be treated in greater detail. Carroll and Gannon (1997) draw on a number of different sources and provide insights into the relationship between culture and ethical behavior, without elaborating any systematic propositions. Stajkovic and Luthans (1997) develop a social cognitive model that examines how individuals perceive ethical problems based on cognitive assessments, using self-regulative processes influenced by institutional constraints, organizational circumstances, and personal values, all of which are shaped by the cultural context. Finally, Robertson and Fadil (1999) begin to explore some of the ways the cultural dimension of individualismcollectivism relates to justice-based moral reasoning.

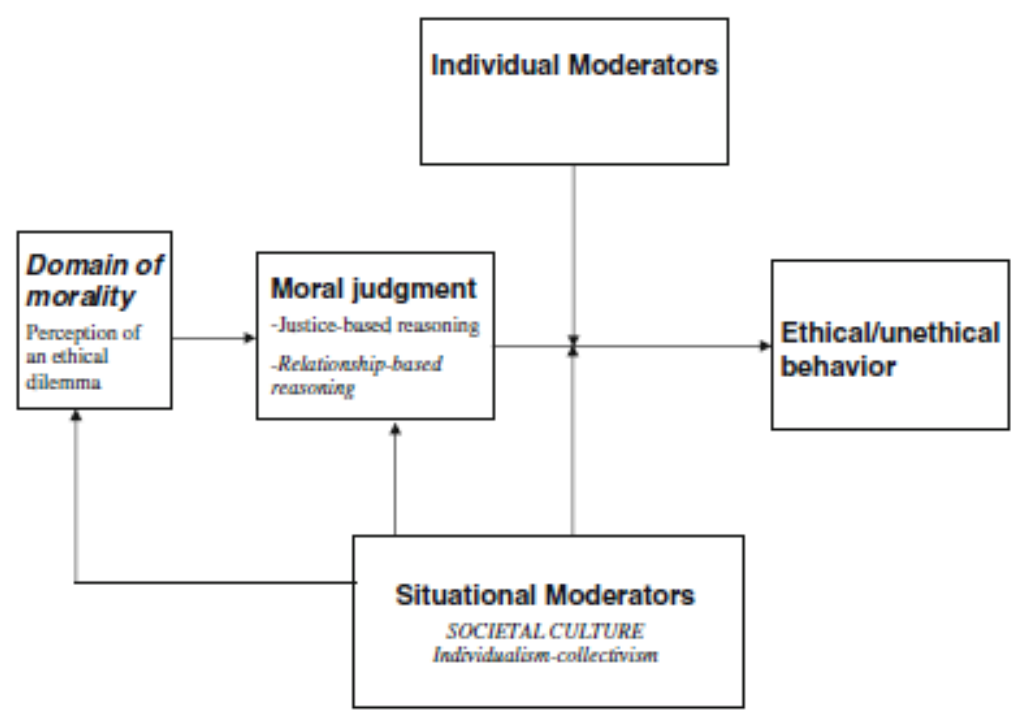

Figure 1. Modification of Trevino's model of ethical decision making including societal culture. Source: Trevino (1986). Modifications indicated in italics.

We build on this prior work and examine how individualism and collectivism affect each of the main elements of the Trevino (1986) model: the inclusion of practices within the moral domain (perception of moral issues), moral judgment, and ethical behavior. In her model, ethical dilemmas are evaluated by individuals using criteria provided by both the person (personality attributes) and the sit- uation (organization culture, job characteristics, and work context). Our modified model postulates that societal culture, as a group-level construct (Brett et al., 1997), is an additional criterion that informs the decision-making process because an individual's values are shaped by the values of his or her cultural group. Thus, the proposed model is a crosslevel model that examines the relationship of the group- level construct of culture to ethical decision making by individuals (see Figure 1).

Ethical decision making is affected by individualism and collectivism because they deal with beliefs about the priority of individual versus group interests (Oyserman et al., 2002; Triandis, 1995). Erez and Earley (1993, p. 
95) conceptualize individualism and collectivism as: "[A] set of shared beliefs and values of a people concerning the relationship of an individual to aggregates or groups of individuals. It represents the way individuals relate to others in their society, and it reflects their emotional and cognitive attachments to particular networks of individuals." Individualism and collectivism, more than other cultural dimensions, affect ethical decision making, which concerns the way people resolve conflicts in human interests and optimize mutual benefits. Specifically, we argue that individualism and collectivism affect the way people perceive, judge, and behave with respect to these conflicts. People who emphasize group goals over individual goals resolve conflicts and optimize benefits in very different ways than people who emphasize individual goals. As a result, practices like software sharing or job security are treated differently by people in individualist and collectivist cultures.

Despite the relevance of individualism and collectivism to ethical decision making, Earley and Gibson (1998) called for a moratorium on further research, pointing to conceptual problems and arguing that other cultural variables had been neglected by international management scholars. However, there are good reasons for lifting the moratorium. First, although there has been confusion in conceptualizing the dimensions of individualism and collectivism and their units of analysis, a careful treatment of these issues should allow for their use in a way that will add to clarity. Second, as Earley and Gibson (1998) themselves mention, the moral impact of individualism and collectivism has not been well developed. Most models have employed them in an overly simplistic way, without explaining how or why it has micro-level effects (Robertson and Fadil, 1999; Vitell et al., 1993). Such an approach is no longer adequate (Earley and Gibson, 1998). Given the lack of research into the impact of individualism and collectivism on ethical behavior, the moratorium should be lifted in this case.

We begin by reviewing the concept of individualism-collectivism as it is discussed in the international management and cross-cultural psychology literatures. We then present Trevino's (1986) model of ethical decision making in business and study the relationship of individualism and collectivism to the main elements of her model: the perception of a moral problem, moral judgment, and ethical behavior. Finally, the paper ends by drawing some general conclusions about the problem of developing a model of cross-cultural business ethics and by suggesting some directions for future research.

\section{A cross-cultural model of ethical decision making}

The cultural dimensions of individualism and collectivism.

Although Geert Hofstede did not invent the terms "individualism" and "collectivism," his initial study focused attention on them and continues to have a significant impact on the field of cross-cultural management (Peterson, 2003). Hofstede (1984) treated individualism and collectivism as a single continuum dealing with the extent to which the ties between individuals are loose or tight. Loose ties between people characterize those cultures in which the individual seeks primarily his or her own interests and those of the immediate family. In collectivist cultures, tight ties bind people into cohesive groups that go beyond the immediate family and demand loyalty throughout a person's life.

More recently, scholars have begun to treat individualism and collectivism as two independent dimensions (Man and Lam, 2003; Oyserman et al., 2002). So for example, people may score high on both the individualism and collectivism dimensions. According to Oyserman et al. (2002), the core elements of individualism are independence and uniqueness, while the core elements of collectivism are duty to the ingroup and, in cross-national contexts, maintenance of harmony. The in-group refers to a group of people sharing similar beliefs and interests and which typically excludes outsiders (Chen and Li, 2005).

Current research now suggests that individualism and collectivism are not inherent elements of culture, but rather are attributes that may arise depending upon the situation (Oyserman, 2006; Oyserman et al., 2002; Torelli, 2006). Different types of cues from the environment can enable the individual to access either individualism or collectivism. Institutional theories of culture suggest that institutions structure incentives 
that make individualism or collectivism more or less beneficial (Chen and Li, 2005; Voronov and Singer, 2002). Hence, cultures differ to the extent that they provide situations or institutions which cue individualism or collectivism.

Individualism and collectivism are especially relevant to questions related to how people work (Erez and Earley, 1993) and thus to many questions of business ethics. Earley (1993) has shown that individualists perform tasks better when working alone than when working with others, but that collectivists perform better working with other members of their in-group than with members of out-groups or alone. Erez and Somech (1996) have found that individualism and collectivism have a moderating effect on group performance loss. In addition, Iwao and Triandis (1993) have shown that the behavior of collectivists and individualists is very similar with respect to universalistic issues (abstract issues that concern society in general). However, with respect to particularistic issues, which involve the specific in-group in question, individualists and collectivists behave differently. They found that Japanese and U.S. subjects responded similarly to universalistic issues involving capital punishment and TV violence, but differently with respect to questions of inter-racial marriage, which affect the in-group.

Individualism and collectivism present special problems with respect to the level of analysis because the construct has been conceptualized both as a societal-level variable (Hofstede, 1984; House et al., 1997) and as an individual-level variable (Earley, 1989, 1993). Cultural variables often operate at both levels because culture is always a collective phenomenon, which at the same time consists of values held by individuals (Hofstede, 1997). Thus, individualism and collectivism may be measured at both levels of analysis. This article looks at these dimensions at the individual level because it is interested in their role in the ethical reasoning processes of the individual manager.

The individualism and collectivism dimensions actually constitute syndromes of attributes that differentiate cultures. A cultural syndrome is "a pattern characterized by shared beliefs, attitudes, norms, roles, and values that are organized around a theme and that can be found in certain geographic regions during a particular historic period" (Triandis, 1995, p. 43). Recent work has begun to divide individualism and collectivism into four related attributes: (1) conceptions of the self, (2) goal relationships, (3) relative importance of beliefs and norms, and (4) emphasis on relationships (Chen et al., 1998; Triandis and Bhawuk, 1997; Triandis et al., 1988).

The conception of the self refers to the way in which an individual understands herself or himself in relationship to others. According to Erez and Earley (1993), "the self is a person's mental representation of his/her own personality, social identity, and social roles...." In an individualist culture, the person tends to perceive him or herself as an independent self who pursues his or her own interests and projects, while in collectivist cultures, the person tends to perceive the self in an interdependent relationship with others (Markus and Kitayama, 1991). The priority of personal and group goals also depends upon individualism and collectivism. In individualist cultures, personal goals tend to take priority over group goals, while in collectivist cultures, group goals are more likely to have priority (Iwao and Triandis, 1993; Triandis et al., 1988). Similarly, the importance of personal beliefs and attitudes with respect to group norms and duties varies with individualism and collectivism. In collectivist cultures, group norms and duties tend to be more important in making decisions by an interdependent self than are personal beliefs and rights. In contrast, the independent self is able to withstand social pressure and relies more on personal beliefs (Torelli, 2006). Finally, in individualist cultures, people tend to place greater importance on achieving tasks than on maintaining harmonious relationships (Oyserman et al., 2002). In collectivist cultures, people are more likely to sacrifice task achievement for the sake of good relationships with others (Triandis, 1995).

Recent work has begun to break down individualism and collectivism into horizontal and vertical components (Chen and Li, 2005; Chen et al., 1997; Oyserman, 2006; Shavitt et al., 2006b; Triandis, 1995; Triandis et al., 1998). The horizontal dimension of individualism and collectivism focuses on the sameness of the self with respect to others. The vertical dimension of individualism and collectivism focuses on the differences or uniqueness of the self with respect to others. We can thus specify at least four possibilities with respect to 
individualism and collectivism: horizontal collectivism, vertical collectivism, horizontal individualism, and vertical individualism.

Horizontal collectivism is focused on cooperation with others (Drach-Zahavy, 2004; Shavitt et al., 2006a). It is especially concerned with the relation- ship of the self to interdependent others. The culture of an Israeli kibbutz is a good example of horizontal collectivism. In contrast, vertical collectivism is focused on duty to the collectivity as a whole. For example, Chen et al. (1997) found that Chinese vertical collectivists were supportive of the reform of reward allocation practices and horizontal collectivists were resistant. These reforms involved rewarding performance according to work, even though such incentives might cause income inequality. Horizontal collectivists resisted such reforms as contrary to their value system, while the vertical collectivists supported such reforms if they were good for the collective as a whole.

Horizontal individualism deals with an independent self that views him or herself as the same as others. The vertical individualist views the independent self as fundamentally different from other independent selves (Chen and Li, 2005). For example, the Swedes are horizontally individualistic because they do not like people to stand out (Triandis, 1995, p. 45). They also are willing to accept a much higher level of income taxes than in the United States, a vertically individualistic country. In the United States, people try to stand out and achieve more than others. There is a strong sense of competition in vertically individualist countries.

Researchers relate individualism and collectivism to morality in a number of ways. First, Triandis and Bhawuck (1997) argue that deviations from group norms are much less tolerated by people in collectivist cultures than by people in individualist cultures. Second, in collectivist cultures, morality is defined in terms of the good of the in-group, which requires the maintenance of solidarity. In other words, those actions that preserve the solidarity of the in-group are morally good (Cohen et al., 2006). Finally, the tension between the fundamental values of equity and equality is resolved differently across cultures. In individualist cultures, equity is preferred over equality, while in collectivist cultures, equity is preferred in dealing with out-groups only, but equality is preferred in dealing with the in-group (Oyserman et al., 2002; Triandis, 1994a, b). Let us now examine the relationship of $\mathrm{I}-\mathrm{C}$ to each of the three main elements of the moral decision-making model.

\section{The perception of the moral problem and the domain of morality}

Ethical decision making begins with the recognition that a particular problem falls within the moral domain (Brady and Hatch, 1992; Jones, 1991; Rest, 1986; Trevino, 1986). The moral domain refers to the set of activities that are subject to judgments of right and wrong as opposed to judgments of personal liking or other kinds of judgments (Colby and Kohlberg, 1987).

Haidt et al. (1993) have shown that the domain of morality is culturally dependent. In other words, the issues considered as ethical vary from culture to culture. Although activities that harm others physically and psychologically are condemned almost universally, there is a large group of harmless or victimless practices that may be accepted in some cultures and rejected in others. Those cultures with a moralizing stance have a much broader domain of morality, while those with a permissive stance have a much narrower domain of morality. Most western societies currently hold a permissive stance toward activities that produce no harmful consequences for the actors involved or other third parties.

Around the world, there appear to be at least three principal moral domains that have been socially constructed (Gergen, 1999): the ethics of autonomy, the ethics of community, and the ethics of divinity (Shweder, 1990). According to Haidt et al. (1993), the ethics of autonomy is defined in terms of avoiding harm to the individual. Much of Western justice involves the delineation of rights and duties to protect the individual from harm (Kant, 1785; Rawls, 1971). In contrast, the moral domain for the ethics of community is characterized by issues of disrespect and harm to the solidarity of the in-group (Shweder, 1990; Triandis, 1995). For the ethics of divinity, the moral domain is defined by violations of the holiness code, which provoke a reaction of disgust (Haidt et al. 1993). This latter code is less relevant to contemporary business 
practice than the former two, although of importance in Islamic cultures, where issues related to holiness are central to business ethics (Rice, 1999; Rippin, 1990). One of the challenges for cross-cultural business ethics is to determine why individuals from a given culture include certain business practices within the moral domain, and exclude others.

Individualism and collectivism influence the decision maker's inclusion of a business practice within the moral domain. Allegedly questionable business practices are perceived by the self, using criteria provided by cultural values and group norms (Erez and Earley, 1993; Stajkovic and Luthans, 1997). In collectivist cultures, people are more likely to define themselves in terms of group membership and place great value on its welfare (Oyserman et al., 2002; Triandis, 1995). People are more likely to perceive negatively business practices that are inconsistent with the welfare of the collective (Erez and Earley, 1993). In contrast, in individualist cultures, people are more likely to perceive themselves as autonomous and place a higher value on their individual interests. So, while duty, hierarchy, and interdependency are at the crux of what is moral in collectivist cultures, harm and rights form the basis of an individualistic moral domain (Shweder, 1990). In collectivist cultures, non-life- threatening violations of social responsibilities are likely to be viewed in moral terms, whereas they are viewed as matters of personal choice in individualist countries (Miller et al., 1990). Thus, in collectivist cultures, decision makers are more likely to identify business practices that harm the maintenance of harmonious relationships within the firm as falling within the moral domain, e.g., layoffs. In individualist cultures, decision makers would probably view such a practice as merely a business decision (Nyaw and Ng, 1994, p. 550).

In more individualist cultures, decision makers are likely to identify practices affecting individual welfare as being within the moral domain. For example, companies in India routinely promise jobs to the children of employees when they reach legal age (Donaldson and Dunfee, 1999). Since India has a highly collectivist culture that values the extended family, such a practice fosters group welfare and does not violate their sense of morality. However, in an individualist culture, such a practice falls within the moral domain because it causes harm to autonomous individuals, specifically qualified job candidates who are not children of employees.

Individualists share a concern for the priority of the rights of the individual. As a result, they will characterize as unethical those organizational practices that affect adversely the interests of individuals, such as sexual and racial discrimination, invasion of privacy, replacing employees without proper notice, and unfair treatment of employee complaints. Given that collectivists generally give preference to the in-group over the out-group, one would expect that collectivists would be less sensitive to issues in which the organization (ingroup) harms the larger community or customers (out-group) than would be individualists. Practices of this kind might include environmental pollution, deceitful advertising, undue influence on governmental agencies, and inadequate corporate support for community needs. For example, in a study of the ethical perceptions of Mexican and U.S. purchasing managers, Tadepalli et al. (1999) found that the collectivist Mexican purchasing managers were much more tolerant of making exaggerated statements to suppliers (outgroup) in order to gain concessions than were the more individualistic U.S. purchasing managers. Similarly, Armstrong and Sweeney (1994) found that collectivist Hong Kong managers were more tolerant than individualist Australian managers of a series of questionable marketing practices that were harmful to customers. Thus, we propose:

Proposition 1: Relative to their counterparts in more individualist cultures, decision makers in collectivist cultures are more likely to include within the moral domain business practices that adversely affect the welfare of the in-group.

Proposition 2: Relative to their counterparts in more collectivist cultures, decision makers in individualist cultures are more likely to include within the moral domain business practices that adversely affect individual welfare.

The horizontal and vertical dimensions of individualism and collectivism also have a significant impact on the individual's inclusion of issues within the moral domain. Chen et al. (1997) note that the ethics of horizontal 
collectivism is focused on interpersonal behaviors, while the ethics of vertical collectivism is focused on the behavior of the individual with respect to the organization. Man and Lam (2003) explain that vertical collectivists feel responsible for the group and are willing to sacrifice themselves for its good. We would expect vertical collectivists to be more likely to perceive as unethical those practices in which the organization is the victim because they are more concerned with loyalty to institutions than either horizontal collectivists or individualists. Such practices might include petty theft of organizational property, inflating reimbursement costs, accepting gifts from suppliers, and employee fraud. In a multicultural study of M.B.A. students, Husted et al. (1996) found that the vertically collectivist Mexican students were less tolerant of employees who falsify their expense accounts than were their more individualist U.S. counterparts. We suggest that this difference in tolerance is due to the greater organizational loyalty of vertical collectivists. Thus, it is proposed:

Proposition 3: Relative to their counterparts in other cultures, decision makers in cultures characterized by vertical collectivism are more likely to include within the moral domain business practices by employees that harm the firm and owners.

Horizontal collectivists value cooperation with others (Drach-Zahavy, 2004; Shavitt et al., 2006a). Consequently, they are more likely to perceive as unethical those practices in which the relationships between employees are threatened than are individuals from other cultures. Unhealthy competition among employees, inadequate communication between departments, lack of teamwork, taking revenge against a work companion, and social loafing are practices that would more likely fall within the domain of unethical work practices for the horizontal collectivist (Erez and Somech, 1996). Thus, we propose:

Proposition 4: Relative to their counterparts in other cultures, decision makers in cultures characterized by horizontal collectivism will be more likely to include within the moral domain business practices that harm relationships among employees.

\section{Moral judgment}

Moral judgment refers to "a mode of prescriptive valuing of the obligatory or right" (Colby and Kohlberg, 1987, p. 9). Thus, it deals with duties and responsibilities, rather than personal preferences. Trevino (1986) uses Lawrence Kohlberg's $(1969,1971)$ theory of moral development in her model. Kohlberg's theory has been widely used in research to understand the reasons individuals use in making moral judgments (Snarey, 1985; Trevino, 1992). However, work by Gilligan $(1977,1982)$ indicates that moral reasoning is much broader than the narrowly focused justice-approach of Kohlberg. Gilligan $(1977,1982)$ has demonstrated that there are at least two different modes of moral reasoning: a relationship-based mode as well as a justice-based mode. Let us examine both approaches in greater detail.

Kohlberg proposed that as people mature and acquire more education and experience, their moral reasoning develops according to a well-defined sequence of stages. Each successive stage requires more complex thinking and involves the individual's consideration of an increasingly wide range of persons and institutions. Kohlberg divides moral development into three major levels and six stages: pre-conventional (stages 1 and 2), conventional (stages 3 and 4), and post-conventional (stages 5 and 6) reasoning. A very brief description of each follows.

The pre-conventional level focuses on the self. In stage 1, the person acts in a moral way as a form of obedience to externally imposed rules in order to avoid punishment (Conry and Nelson, 1989). In stage 2, the person acts morally because it is in her or his self-interest to act in such a way (Conry and Nelson, 1989). In each case, the person obeys authorities to avoid personal harm and gain rewards.

The conventional level focuses on the in-group of family, friends, and peers. For persons at stage 3, "morality is viewed in terms of creating and nurturing long-term relationships of mutual support" with members of 
one's in-group (Conry and Nelson, 1989). Morality at stage 4 consists of upholding law and order. Here, the in-group expands to include one's larger community.

The post-conventional level focuses on society or humanity in general. Stage 5 conceives of morality as compliance with the social contract. Rules are understood to be relative to a particular group, but are upheld in the interest of impartiality (Colby and Kohlberg, 1987). Stage 6 , the highest stage in Kohlberg's hierarchy, "is based on commitment to rational, abstract, self-selected universal principles for governing social cooperation."

Although Kohlberg $(1969,1971)$ thought that the structure and sequence of the six stages were universal, some theorists have argued that these structures and sequences may vary in different cultures (Shweder, 1982). There exists some evidence that moral reasoning as conceived by Kohlberg is related to culture (Rest, 1986; Robertson and Fadil, 1999; Snarey, 1985). Snarey's (1985) review of 45 empirical studies carried out in 27 countries found that stages 1 through 4 appear to be universal. However, the post-conventional stages were not universal (Ma, 1988a; Ma and Cheung, 1996; Snarey, 1985). Snarey (1985) argued that Kohlberg's work should be supplemented with a theory of post-conventional moral reasoning that includes developmental paths appropriate for different cultures.

According to Kohlberg $(1969,1971)$, at the post-conventional level (stages 5 and 6), people evaluate morality in terms of concepts of rights and fairness based on judgments of equality, merit, and equity (Colby and Kohlberg, 1987). These concepts assume that people are autonomous individuals who undertake selfimposed obligations that apply to all, regardless of personal connections to in-group members (Gilligan, 1982; Kant, 1785; Rawls, 1971, p. 13). In individualist cultures, personal identity is based on the independent self, rather than the interdependent self-immersed in a web of relationships (Earley and Erez, 1993). Thus, we expect that in individualist cultures, people are more likely to use justice-based reasoning than people from collectivist cultures. This expectation is supported by Husted et al. (1996) who found that individualistic U.S. MBA students were more likely to use justice-based post-conventional reasoning than were either the Spanish or Mexican students.

Proposition 5: Relative to their counterparts in more collectivist cultures, decision makers in individualist cultures are more likely to use justice-based post- conventional moral reasoning.

In contrast to the justice model of moral reasoning developed by Kohlberg, models of relationship-based post-conventional moral reasoning are emerging, which emphasize a duty to care for relationships with others (Gergen, 1991; Gilligan 1977, 1982; Ma, 1988b; Sandel, 1982, Skoe et al., 1999).

In relational models, post-conventional moral reasoning takes a universal perspective without neglecting obligations to particular members of the in-group (Gilligan, 1982; Ma, 1988b). Reasoning about deviant and pro-social behavior tends to be more contextualized by appealing to situational circumstances. In addition, collectivists find relational explanations to be more persuasive (Oyserman et al., 2002). In collectivist cultures, people are more likely to develop relationship-based modes of post-conventional reasoning than in individualist cultures because the collectivist concept of the self is inherently interdependent (Iwao and Triandis, 1993; Triandis, 1995). The self is "an intersection of multiple relationships" (McNamee and Gergen, 1999).

An example may help distinguish the two modes of post-conventional moral reasoning. Kohlberg's moral judgment interview includes a scenario entitled, "Heinz and the Drug," in which Heinz must decide whether to steal a very expensive drug in order to save his wife's life. Kohlberg hypothesized that Heinz would steal the drug because his wife's right to life supersedes the right to property - a justice orientation (Colby and Kohlberg, 1987, p.317). In contrast, a Chinese respondent used relationship-based reasoning when he stated:

Everyone should try his best to save other's life because the society is composed of men, and if people don't care for others, the world would become very horrible. As a man, one should have the spirit of 'loving others 
as loving yourself.' (Ma, 1988b, p. 214)

Empirical research seems to confirm that the post- conventional moral reasoning of people from collectivist cultures, like South Asians (Miller and Bersoff, 1992) and Mexican Americans (Gump et al., 2000), tends to be relationship based, while the moral reasoning of people from more individualist cultures tends to be justice based.

Proposition 6: Relative to their counterparts in more individualist cultures, decision makers in collectivist cultures are more likely to use relationship-based post-conventional moral reasoning.

\section{Ethical behavior}

After a person makes a judgment about whether a particular action is ethical, the person engages in behavior, which may or may not be consistent with his or her judgment. Reviews of the literature indicate that there is a moderate relationship between moral reasoning and behavior (Blasi, 1980; Thoma and Rest, 1986). According to Trevino (1986), other variables moderate the relationship between moral reasoning and behavior, among which individualism and collectivism can be included.

Specifically, Trevino (1986) includes the individual characteristics of ego strength, field dependence, and locus of control as well as the situational characteristics of immediate job context, organizational culture, and the characteristics of the work. For example, she argues that consistency between moral judgment and behavior is more likely when the organizational culture encourages managers to be responsible for all the consequences of the decisions they make. External pressures such as lack of time, resources, or intense competition will decrease the consistency between reasoning and behavior.

Individualism and collectivism should also moderate the relationship between moral reasoning and moral behavior. We expect people from individualist cultures to exhibit a stronger consistency between moral reasoning and moral behavior than people from collectivist cultures. There are a number of reasons for this expectation.

First, individualism and collectivism moderate the relationship between moral judgment and behavior because of its sub-dimension regarding the relationship of beliefs and norms. In individualist cultures, personal beliefs are more important in decision making than are group norms (Iwao and Triandis, 1993; Oyserman et al., 2002). In collectivist cultures, people may hold personal beliefs (private self) that differ significantly from the group norm (public self), but will behave in accordance with the group norm (Chen et al., 1998; Triandis, 1995). In addition, they tend to accept the discrepancy between their public and private selves (Iwao and Triandis, 1993). In individualist cultures, people are likely to view this difference as hypocritical and try to reduce such discrepancies. As a result, there tends to be greater consistency between personal attitudes and behavior for individuals in individualist cultures than in collectivist cultures (Kashima et al., 1992; Volkema, 1998). Thus, in individualist cultures, people are more likely to behave in accordance with judgments formulated as a result of moral reasoning than will their collectivist counterparts.

Second, collectivists place greater emphasis on social norms and expectations and the roles they fulfill in relationship to others. In essence, collectivists are higher in field dependence, one of the variables that moderates the moral reasoning-moral behavior relationship in Trevino's (1986) model. Field dependence refers to the extent to which individuals make use of external social referents to guide their behavior. Field independent people are more autonomous in their decision making and exhibit more consistency between moral reasoning and moral action than field-dependent managers (Trevino, 1986). Since one would expect persons from individualistic cultures to be higher in field independence than persons from collectivist cultures, one would also expect individualists to exhibit greater consistency between reasoning and action. Some empirical support for this relationship is provided by Volkema (1998) who has found that there was a greater discrepancy between judgments about the appropriateness of questionable negotiation tactics and the likelihood of their use by collectivist Mexican business professionals and students than by their 
individualist U.S. counterparts. Therefore, it is proposed:

Proposition 7: Relative to their counterparts in more collectivist cultures, decision makers in individualist cultures are likely to exhibit greater consistency between their moral judgments and their behavior.

\section{Conclusions}

The model and propositions developed in this paper provide a conceptual base needed to develop an agenda for future research of ethical decision making in multicultural contexts. The model offers insight into how individualism and collectivism can affect the perception of ethical dilemmas, moral reasoning, and the behavior of individuals in organizations. This model explicitly proposes that different modes of postconventional moral reasoning will be used in different cultures. In addition, it helps culture-spanning managers understand differences in the way ethical decisions are made by organizational members.

The advantage of this approach is that it makes work on cross-cultural business ethics tractable by analyzing a parsimonious model of cultural differences. On the other hand, it may trivialize the very complex nature of the subject it intends to treat (Geertz, 1973; Voronov and Singer, 2002). Yet at this point in the development of a cross-cultural business ethics, it may be the only way that will produce managerially relevant knowledge simply because it may be subject to testing.

This discussion is not meant to be exhaustive, but rather suggestive of the way researchers should approach this field. Future scholars will undoubtedly focus on other cultural dimensions that also influence ethical decision making. Additional challenges arise in attempting to understand the dynamics of ethical decision making among individuals from different cultures. Future research should also explore the way that ethics programs in multi-national corporations are designed so that they include incentives and policies congruent with the culture in which these programs operate.

Further work needs to take into account the impact of institutional factors on the ethical behavior of individuals in organizations across nations. Research on the way institutions may cue individualistic or collectivistic responses by individuals should be especially promising. Given that the same individual will treat one situation by recurring to collectivistic concepts and in another will apply apparently individualistic concepts, it is imperative that we improve how we model the contextual determinants of ethical decision making.

Future research should also examine the interaction between culture and other moderators of ethical decision making. In addition, the social process by which the ethical stances of different individuals combine to form an actual collective choice remains problematic. Finally, researchers should incorporate the impact of the holiness code on the perception of ethical issues and on moral reasoning.

Despite these limitations, the proposed model organizes much prior research and provides a solid conceptual framework for future work by offering a more refined conceptualization and specific predictions about the impact of individualism and collectivism. In addition, the model contributes to managerial practice by providing members of multicultural teams with the tools to begin to understand ethical differences. An understanding of the cultural roots of such differences is likely to help individuals work together more effectively. 
Marketing Ethics Problems: A Cross-Cultural Comparison', Journal of Business Ethics 13, 775-785.

Blasi, A.: 1980, 'Bridging Moral Cognition and Moral Action: A Critical Review of the Literature', Psychological Bulletin 88, 1-45.

Brady, F. N. and M. J. Hatch: 1992, 'General Causal Models in Business Ethics: An Essay on Colliding Research Traditions', Journal of Business Ethics 11, 307-315.

Brett, J. M., C. H. Tinsley, M. Janssens, Z. I. Barsness and A. L. Lytle: 1997, 'New Approaches to the Study of Culture in Industrial/Organizational Psychology', in P. C. Earley and M. Erez (eds.), New Perspectives on International Industrial/Organizational Psychology (The New Lexington Press, San Francisco), pp. 75-129.

Carroll, S. J. and M. J. Gannon: 1997, Ethical Dimensions of International Management (Sage Publications, Thou- sand Oaks, CA).

Chen, C. C., X.-P. Chen and J. R. Meindl: 1998, 'How can Cooperation be Fostered? The Cultural Effects of Individualism-Collectivism', Academy of Management Review 23(2), 285-304.

Chen, X. P. and S. Li: 2005, 'Cross-National Differences in Cooperative Decision-Making in Mixed-Motive Business Contexts: The Mediating Effect of Vertical and Horizontal Individualism', Journal of International Business Studies 36, 622-636.

Chen, C. C., J. R. Meindl and R. G. Hunt: 1997, 'Testing the Effects of Vertical and Horizontal Collectivism: A Study of Reward Allocation Preferences in China', Journal of Cross-Cultural Psychology 28(1), 44-70.

Cohen, T. R., R. M. Montoya and C. A. Insko: 2006, 'Group Morality and Intergroup Relations: Cross- Cultural and Experimental Evidence', Personality and Social Psychology Bulletin 32(11), 1559-1572.

Cohen, J. R., L. W. Pant and D. J. Sharp: 1996, 'A Methodological Note on Cross-Cultural Accounting Ethics Research', International Journal of Accounting 31(1), 55-66.

Colby, A. and L. Kohlberg: 1987, The Measurement of Moral Judgment (Cambridge University Press, Cambridge).

Conry, E. J. and D. R. Nelson: 1989, 'Business Law and Moral Growth', American Business Law Journal 27(1), 1-39.

Donaldson, T.: 1996, 'Values in Tension: Ethics Away from Home', Harvard Business Review 74(5), 48-62. Donaldson, T. and T. Dunfee: 1999, The Ties that Bind: A Social Contracts Approach to Business Ethics (Harvard Business School Press, Boston).

Drach-Zahavy, A.: 2004, 'The Proficiency Trap: How to Balance Enriched Job Designs and the Team's Need for Support', Journal of Organizational Behavior 25, 979-996.

Earley, P. C.: 1989, 'Social Loafing and Collectivism', Administrative Science Quarterly 34, 565-581.

Earley, P. C.: 1993, 'East Meets West Meets Mideast: Further Explorations of Collectivistic and Individualistic Work Groups', Academy of Management Journal 36(2), 319-348.

Earley, P. C. and C. B. Gibson: 1998, 'Taking Stock in Our Progress on Individualism-Collectivism: 100 Years of Solidarity and Community', Journal of Management 24(3), 265-304.

Erez, M. and P. C. Earley: 1993, Culture, Self-Identity, and Work (Oxford University Press, New York).

Erez, M. and A. Somech: 1996, 'Is Group Productivity Loss the Rule or The Exception? Effects of Culture and Group-Based Motivation', Academy of Management Journal 39, 1513-1537.

Geertz, C.: 1973, The Interpretation of Culture (Basic Books, New York).

Gergen, K. J.: 1991, The Saturated Self: Dilemmas of Identity in Contemporary Life (Basic Books, New York). Gergen, K. J.: 1999, An Invitation to Social Construction (Sage Publications, London).

Gilligan, C.: 1977, 'In a Different Voice: Women's Conception of Self and of Morality', Harvard Educational Review 47, 481-517.

Gilligan, C.: 1982, In a Different Voice (Harvard University Press, Cambridge).

Gump, L. S., R. C. Baker and S. Roll: 2000, 'Cultural and Gender Differences in Moral Judgement: A Study of Mexican Americans and Anglo-Americans', Hispanic Journal of Behavioral Sciences 22(1), 78-93.

Haidt, J., S-H. Koller and M. G. Dias: 1993, 'Affect, Culture, and Morality, or Is It Wrong to Eat Your Dog?', Journal of Personality and Social Psychology 65(4), 613-628.

Hardin, R.: 1988, Morality Within the Limits of Reason (University of Chicago Press, Chicago).

Hofstede, G.: 1984, Culture's Consequences (Sage, Beverly Hills).

Hofstede, G.: 1997, Cultures and Organizations: Software of the Mind (McGraw Hill, New York ).

House, R. J., N. S. Wright and R. N. Aditya: 1997, 'Cross-Cultural Research on Organizational Leadership: A Critical Analysis and a Proposed Theory', in P. C. Earley and M. Erez (eds.), New Perspectives on International 
Industrial/Organizational Psychology (New Lexington Press, San Francisco, CA), pp. 535-625.

Husted, B. W., J. B. Dozier, J. T. McMahon and M. W. Kattan: 1996, 'The Impact of Cross-National Carriers of Business Ethics on Attitudes About Questionable Practices and Form of Moral Reasoning', Journal of International Business Studies 27(2), 391-411.

Iwao, S. and H. C. Triandis: 1993, 'Validity of Auto- and Heterostereotypes Among Japanese and American Students', Journal of Cross-Cultural Psychology 24(4), 428-444.

Janis, I.: 1982, Groupthink: Psychological Studies of Policy Decisions and Fiascoes (Houghton Mifflin, Boston). Jones, T. M.: 1991, 'Ethical Decision Making by Individuals in Organizations: An Issue-Contingent Model', Academy of Management Review 16(2), 366-395.

Kant, I.: 1964[1785], Groundwork of the Metaphysic of Morals (Harper and Row, New York).

Kashima, Y., M. Siegel, K. Tanaka and E. S. Kashima: 1992, 'Do People Believe Behaviors are Consistent with Attitudes? Toward a Cultural Psychology of Attribution Processes', British Journal of Social Psychology 331, 111-124.

Kohlberg, L.: 1969, 'Stage and Sequence: The Cognitive Developmental Approach to Socialization', in D. A. Goslin (ed.), Handbook of Socialization Theory and Research (Rand-McNally, Chicago).

Kohlberg, L.: 1971, 'From is to Ought: How to Commit the Naturalistic Fallacy and Get Away with It in the Study of Moral Development', in T. Mischel (ed.), Cognitive Development and Epistemology (Academic Press, New York).

Ma, H. K.: 1988a, 'Objective Moral Judgment in Hong Kong, Mainland China, and England', Journal of CrossCultural Psychology 19(1), 78-95.

Ma, H. K.: 1988b, 'The Chinese Perspectives on Moral Judgment Development', International Journal of Psychology, 23, 201-227.

Ma, H. K. and C.-K. Cheung: 1996, 'A Cross-Cultural Study of Moral Stage Structure in Hong Kong Chinese, English, and Americans', Journal of Cross-Cultural Psychology 27(6), 700-713.

Man, D. C. and S. S. K. Lam: 2003, 'The Effects of Job Complexity and Autonomy on Cohesiveness in Collectivistic and Individualistic Work Groups: A Cross-Cultural Analysis', Journal of Organizational Behavior 24(8), 979-1001.

Markus, H. R. and S. Kitayama: 1991, 'Culture and the Self: Implications for Cognition, Emotion, and Motivation', Psychological Review 98, 224-253.

McNamee, S. and K. J. Gergen: 1999, Relational Responsibilities: Resources for Sustainable Dialogue (Sage, Thousand Oaks).

Miller, J. G. and D. M. Bersoff: 1992, 'Culture and Moral Judgment: How are Conflicts Between Justice and Interpersonal Responsibilities Resolved?', Journal of Personality and Social Psychology 62, 541-554.

Miller, J. G., D. M. Bersoff and R. L. Harwood: 1990, 'Perceptions of Social Responsibilities in India and in the United States: Moral Imperatives or Personal Decisions?', Journal of Personality and Social Psychology 58(1), 33-47.

Nyaw, M-K. and I. Ng: 1994, 'A Comparative Analysis of Ethical Beliefs: A Four Country Study', Journal of Business Ethics 13, 543-555.

Oyserman, D.: 2006, 'High Power, Low Power, and Equality: Culture Beyond Individualism and Collectivism', Journal of Consumer Psychology 16(4), 352-356.

Oyserman, D., H. M. Coon and M. Kemmelmeier: 2002 'Rethinking Individualism and Collectivism: Evaluation of Theoretical Assumptions and Meta-Analyses', Psychological Bulletin 128(1), 3-72.

Peterson, M. F.: 2003, 'Culture's Consequences: Comparing Values, Behaviors, Institutions, and Organizations Across Nations', Administrative Science Quarterly 48(1), 127-131.

Rawls, J.: 1971, A Theory of Justice (Harvard University Press, Cambridge).

Rest, J. R.: 1986, Moral Development: Advances in Research and Theory (Praeger Publishers, New York).

Rice, G.: 1999, 'Islamic Ethics and the Implications for Business', Journal of Business Ethics 18, 345-358. Rippin, A.: 1990, Muslims: Their Religious Beliefs and Practices (Routledge, London).

Robertson, C. and P. A. Fadil: 1999, 'Ethical Decision Making in Multinational Organizations: A Culture-Based Model', Journal of Business Ethics 19, 385-392.

Sandel, M. J.: 1982, Liberalism and the Limits of Justice (Cambridge University Press, Cambridge).

Shavitt, S., A. K. Lalwani, J. Zhang and C. J. Torelli: 2006a, 'The Horizontal/Vertical Distinction in CrossCultural Consumer Research', Journal of Consumer Psychology 16(4), 325-343. 
Shavitt, S., J. Zhang, C. J. Torelli and A. K. Lalwani: 2006b, 'Reflections on the Meaning and Structure of the Horizontal/Vertical Distinction', Journal of Consumer Psychology 16(4), 357-362.

Shweder, R. A.: 1982, 'Beyond Self-Constructed Knowledge: The Study of Culture and Morality', MerrillPalmer Quarterly 28(1), 41-69.

Shweder, R. A.: 1990, 'In Defense of Moral Realism: Reply to Gabennesch', Child Development 61, 20602067.

Skoe, E. E. A., K. L. Hansen, W.-T. Morch and I. Bakke, et al.: 1999, 'Care-Based Moral Reasoning in Norwegian and Canadian Early Adolescents: A Cross-National Comparison', The Journal of Early Adolescence 19(2), 280292.

Snarey, J. R.: 1985, 'Cross-Cultural Universality of Social-Moral Development: A Critical Review of Kohlbergian Research', Psychological Bulletin 97, 202-232.

Stajkovic, A. D. and F. Luthans: 1997, 'Business Ethics Across Cultures: A Social Cognitive Model', Journal of World Business 32(1), 17-34.

Swinyard, W. R., H. Rinne and A. K. Kau: 1990, 'The Morality of Software Piracy: A Cross-Cultural Analysis', Journal of Business Ethics 9(8), 655-664.

Tadepalli, R., A. Moreno and S. Trevino: 1999, 'Do American and Mexican Purchasing Managers Perceive Ethical Situations Differently?', Journal of Business Ethics 28, 369-380.

Thoma, S. J. and J. Rest (with R. Barnett): 1986, 'Moral Judgment, Behavior, Decision Making, and Attitudes', in J. Rest (ed.), Moral Development: Advances in Research and Theory (Praeger, New York).

Torelli, C. J.: 2006, 'Individuality or Conformity? The Effect of Independent and Interdependent Self-Concepts on Public Judgments', Journal of Consumer Research 16(3), 240-248.

Trevino, L. K.: 1986, 'Ethical Decision Making in Organizations: A Person-Situation Interactionist Model', Academy of Management Review 11, 601-617.

Trevino, L. K.: 1992, 'Moral Reasoning and Business Ethics: Implications for Research, Education, and Management', Journal of Business Ethics 11, 445-459.

Trevino, L. K., K. D. Butterfield and D. L. McCabe: 1998, 'The Ethical Context in Organizations: Influence on Employee Attitudes and Behaviors', Business Ethics Quarterly 8(3), 447-476.

Trevino, L. K. and S. A. Youngblood: 1990, 'Bad Apples in Bad Barrels: A Causal Analysis of Ethical DecisionMaking Behavior', Journal of Applied Psychology 75, 378-385.

Triandis, H. C.: 1994a, 'Cross-Cultural Industrial and Organizational Psychology', in H. C. Triandis, M. D. Dunnette and L. M. Hough (eds.), Handbook of Industrial and Organizational Psychology, vol. 4, edn. 2 (Consulting Psychologists Press, Palo Alto, CA), pp.103-172.

Triandis, H. C.: 1994b, Culture and Social Behavior (McGraw-Hill, New York, NY).

Triandis, H. C.: 1995, Individualism and Collectivism (Westview Press, Boulder).

Triandis, H. C. and D. P. S. Bhawuk: 1997, 'Culture Theory and the Meaning of Relatedness', in P. C. Earley and M. Erez (eds.), New Perspectives on International Industrial/Organizational Psychology (The New Lexington Press, San Francisco), pp. 13-52.

Triandis, H. C., R. Bontempo, M. J. Villareal, M. Asai and N. Lucca: 1988, 'Individualism and Collectivism: Cross-Cultural Perspectives on Self-Ingroup Relationships', Journal of Personality and Social Psychology 54, 323-338.

Triandis, H. C., X. P. Chen and P. C. Chan: 1998, 'Scenarios for the Measurement of Collectivism and Individualism', Journal of Cross-Cultural Psychology 29(2), 275-289.

Vitell, S. J., S. L. Nwachukwu and J. H. Barnes: 1993, 'The Effects of Culture on Ethical Decision-Making: An Application of Hofstede's Typology', Journal of Business Ethics 12(10), 753-760.

Volkema, R. J.: 1998, 'A Comparison of Perceptions of Ethical Negotiation Behavior in Mexico and the United States', International Journal of Conflict Management 9(3), 218-233.

Voronov, M. and J. A. Singer: 2002, 'The Myth of Individualism-Collectivism: A Critical Review', Journal of Social Psychology 142(4), 461-480.

Wimbush, J. C.: 1999, 'The Effect of Cognitive Moral Development and Supervisory Influence on Subordinates Ethical Behavior', Journal of Business Ethics 18(4), 383-395.

Wines, W. A. and N. K. Napier: 1992, 'Toward an Understanding of Cross-Cultural Ethics: A Tentative Model', Journal of Business Ethics 11, 831-841. 